\title{
Procedure for Haul Truck On-Board LNG Fuel Systems Performance Evaluation
}

\author{
Georgiy Dubov ${ }^{1, *}$, Dmitriy Trukhmanov ${ }^{1}$, Iliya Kuznetsov ${ }^{2}$, Sergey Nokhrin ${ }^{3}$, and Aleksey \\ Sergel $^{4}$ \\ ${ }^{1}$ T.F. Gorbachev Kuzbass State Technical University, Department of Mechanical Engineering Tech- \\ nology, 28 Vesennya st., Kemerovo, the Russian Federation \\ ${ }^{2}$ T.F. Gorbachev Kuzbass State Technical University, Department of Building Structures, Water Sup- \\ ply and Disposal, 28 Vesennya st., Kemerovo, the Russian Federation \\ ${ }^{3} \mathrm{OOO}$ «Sibir-Energo», 13 Schyorsa st., Novokuznetsk, the Russian Federation \\ ${ }^{4} \mathrm{OAO}$ «BELAZ» - Management Company of Holding «BELAZ-HOLDING», 440 let Octyabrya st., \\ Zhodino, Minsk region, Republic of Belarus
}

\begin{abstract}
The state-of-the-art of the advantages of using liquefied natural gas as a motor fuel for haul trucks instead of oil motor fuel is considered. It is noted that the energy intensity of the process of rock mass hauling by dual-fuel (gas-diesel) haul trucks is less than that of haul trucks running on diesel only. It is argued that the most promising in relation to heavy-duty mining trucks, is the conversion of diesel engines to gas-diesel operation. The universal integrated procedure for evaluating currently used haul truck on-board cryogenic fuel systems performance is presented. The method of evaluating the "rate of replacement" of diesel fuel with liquefied natural gas, when operating haul trucks equipped with on-board cryogenic fuel systems, is described in detail. The possible sequence of per-cycle, persingle-shift and per-day monitoring of the rate of diesel fuel replacement with liquefied natural gas is presented. The method for evaluating the economic efficiency of the operation of high-payload-capacity haul trucks conversed to gas-diesel operation is given, which allows, among other things, determining the actual service life of on-board cryogenic fuel systems and their time to failure.
\end{abstract}

\section{Introduction}

The consumption of mineral resources annually increases in the world. In the near future this will lead to a significant need in high-quality mining and processing equipment for mining companies, ensuring ever-increasing environmental requirements for its operation [1].

The Russian government currently pays special attention to the implementation of projects in the field of liquefied natural gas production (President of the Russian Federation:

\footnotetext{
${ }^{*}$ Corresponding author: nikokem@mail.ru
} 
instructions Pr-2699 dated December 25, 2017) and expanding the use of gas as a motor fuel (President of the Russian Federation: instructions Pr-743 dated April 28, 2018).

\section{Material and Methods}

The greatest economic benefit from the use of liquefied natural gas instead of oil motor fuel can be obtained for heavy-duty vehicles, including haul trucks, continuously operating for a long time.

When using liquefied natural gas as a motor fuel, the gas content of open-pit sites involved in open-cast mining is significantly reduced. The use of liquefied natural gas also allows reducing the content of toxic and carcinogenic substances in exhaust gases, increasing engine life, reducing engine oil consumption, reducing engine noise, reducing fuel costs [2-6].

Besides, previous studies suggest that the energy intensity of the process of rock mass hauling by dual-fuel (gas-diesel) haul trucks is less than that of haul trucks using only diesel fuel [7].

The purpose of the presented work is to create the integrated procedure for evaluating performance indicators of haul truck on-board cryogenic fuel systems.

\section{Results and Discussion}

As mentioned earlier, liquefied natural gas seems to be the most promising alternative to oil motor fuels, as confirmed by several studies in this area [8-14].

Two methods are currently used for the use of liquefied natural gas as a motor fuel: gasonly engines are used, and diesel engines are also equipped with on-board cryogenic fuel systems, which allow partial replacement of diesel fuel with natural gas - methane. According to the authors, the conversion of diesel engines to gas-diesel operation is the most promising approach for heavy-duty mining trucks.

This is due to a number of factors, such as:

- the currently available world heavy-duty mining truck fleet is mainly equipped with highpower diesel engines and installation of gas-only engines seems to be economically inexpedient in the near future;

- the conversion of mining haul trucks to gas-diesel operation does not require significant constructive alteration of diesel engine itself, which ensures minimal costs for its upgrading;

- installation of on-board cryogenic fuel systems allows using both diesel-fuelled and gasdiesel mixture-fuelled (dual-fuel gas-diesel operation) haul trucks, which is rather important for harsh climatic conditions of Siberia and the extreme North;

- the payback period of haul truck conversion to gas-diesel operation is short, which guarantees economic benefits.

The integrated procedure was developed to evaluate performance indicators of BelAZ haul truck on-board cryogenic fuel systems used in the Kuzbass mines from 2017.

This procedure allows evaluating the rate $\mathrm{K}_{3}$ of diesel fuel replacement with liquefied natural gas when operating gas-diesel haul trucks, evaluating the economic efficiency of the operation of haul trucks equipped with on-board cryogenic fuel systems.

Consider in detail this procedure.

For the integrated evaluation of performance indicators of on-board cryogenic fuel systems, it is necessary to take into account mining, engineering and technological conditions of haul truck operation, as well as the actual technical state of their units and systems. 
At the initial stage, an experimental upgraded haul truck (EUHT) equipped with an onboard cryogenic fuel system to be used for dual-fuel/gas-diesel operation is chosen. The condition of a EUHT engine and fuel systems should be intact.

Before monitoring, the EUHT driver should receive the appropriate instructions concerning the driving speed, the time of switching from diesel to gas-diesel operation, etc., which he must comply with.

For the period of monitoring and information gathering, a EUHT should be operated in the most identical conditions:

- a EUHT should be operated with one excavator on one route for at least one shift; - a steady speed and, established by standards or requirements of a EUHT operator, should be ensured.

Requirements for the technical state of a EUHT and monitoring systems are as follows:

- a EUHT should be equipped with its performance monitoring systems, including fuel flow meter systems (both diesel and gas fuels) allowing to account for the consumption per unit time;

- monitoring systems should record the time of each stage of a EUHT operation cycle, the distance traveled, the hauled rock mass weight, the driving speed, the fuel consumption, the number/model of the excavator;

- it is necessary to record weather conditions for a more complete evaluation of an on-board cryogenic fuel system performance.

The EUHT driver must alternate the operation modes (diesel and gas-diesel), while ensuring steady speed and smooth ride. Monitoring can be carried out per cycle, single shift (day and night), and day.

\subsection{Per-cycle monitoring}

\subsubsection{1st stage}

The EUHT driver must make two diesel-fuelled hauls in a row. After each diesel-fuelled haul, the diesel fuel flow meter readings are taken and the obtained values are recorded. The total diesel consumption per two diesel-fuelled hauls is determined according to the flow meter readings:

$$
\mathrm{C}_{\text {tot. d-f. }}=\mathrm{C}_{1 \mathrm{~d} \text {-f. }}+\mathrm{C}_{2 \mathrm{~d} \text {-f. }} \text {; }
$$

where, $\mathrm{C}_{\text {tot. d-f. }}$ - the total diesel consumption per two diesel-fuelled hauls, $1 ; \mathrm{C}_{1 \mathrm{~d}-\mathrm{f} \text {. }}$ - the diesel consumption per first diesel-fuelled haul, $1 ; \mathrm{C}_{2 \mathrm{~d}-\mathrm{f} \text {. }}$ - the diesel consumption per second diesel-fuelled haul, 1 .

\subsubsection{2nd stage}

After diesel-fuelled hauls, the EUHT driver makes two mixed gas-diesel-fuelled hauls. After each mixed gas-diesel-fuelled haul, the diesel fuel flow meter readings are taken and the obtained values are recorded. The total diesel consumption per two mixed gas-dieselfuelled hauls is determined according to the obtained values:

$$
\mathrm{C}_{\text {tot. g-d-f. }}=\mathrm{C}_{1 \mathrm{~g} \text {-d-f. }}+\mathrm{C}_{2 \mathrm{~g} \text {-d-f. }} \text {; }
$$


where, $\mathrm{C}_{\text {tot.g-d-f. }}$ - the total diesel consumption per two mixed gas-diesel-fuelled hauls, $1 ; \mathrm{C}_{1 \mathrm{~g}}$ d-f. - the diesel consumption per first mixed gas-diesel-fuelled haul, $1 ; \mathrm{C}_{2 \mathrm{~g} \text {-d-f.- }}$ the diesel consumption per second mixed gas-diesel-fuelled haul, 1 .

\subsubsection{3rd stage}

Using the values obtained by formulas 1 and 2, the rate of diesel fuel replacement with natural gas is determined according to the data of per-cycle monitoring:

$$
\mathrm{R}_{\text {rep. p-c. }}=1-\frac{\mathrm{C}_{\text {tot. g-d-f. }}}{\mathrm{C}_{\text {tot. d-f. }}}
$$

where, $\mathrm{R}_{\text {rep. p-c. }}$ - the rate of diesel replacement with natural gas according to the data of percycle monitoring; $\mathrm{C}_{\text {tot.g-d-f.- }}$ the total diesel consumption per two mixed gas-diesel-fuelled hauls, 1 ; $\mathrm{C}_{\text {tot. d-f. }}$ - the total diesel consumption per two diesel-fuelled hauls, 1 .

If it is necessary to determine the replacement rate in percentage terms, the formula 3 will have the following form:

$$
\mathrm{R}_{\text {rep. p-c. }}=\left(1-\frac{\mathrm{C}_{\text {tot. g-d-f. }}}{\mathrm{C}_{\text {tot. d-f. }}}\right) \times 100 \% \text {; }
$$

\subsection{Per-single-shift monitoring}

Two diesel-fuelled and two mixed gas-diesel-fuelled EUHT hauls should proportionally alternate during single work shift. The number of diesel-fuelled hauls should be two in a row (one after another) and the number of mixed gas-diesel-fuelled hauls should also be two in a row (one after another). For reliability and comparability of the comparative evaluation of the data obtained, it is necessary to carry out an equal and even number of both diesel-fuelled and mixed gas-diesel-fuelled hauls.

\subsubsection{1st stage}

At the first stage, the total value of diesel consumption of all diesel-fuelled EUHT hauls per single shift $\mathrm{C}_{\text {tot. }}$ d-f. p-s-s. is determined by summing up all the obtained and recorded values of diesel fuel consumption:

$$
\mathrm{C}_{\text {tot. d-f. p-s-s. }}=\mathrm{C}_{1 \mathrm{~d}-\text {-f. }}+\mathrm{C}_{2 \mathrm{~d}-\text { f. }}+\ldots \ldots \ldots \ldots \mathrm{C}_{\mathrm{n}+1 \text { d-f. }} \text {; }
$$

where, $\mathrm{C}_{1 \mathrm{~d}-\mathrm{f} \text { - }}$ the diesel consumption per first haul, $1 ; \mathrm{C}_{2 \mathrm{~d} \text {-f.- }}$ the diesel consumption second first haul, $1 ; \mathrm{C}_{\mathrm{n}+1 \mathrm{~d}-\mathrm{f} .}-\mathrm{t}$ the diesel consumption for all subsequent haul pairs per single shift, 1 .

\subsubsection{2nd stage}

At the second stage, the total value of diesel consumption $\mathrm{C}_{\text {tot. }}$-d-d.f. p-s-s. of all mixed gasdiesel-fuelled EUHT hauls per single shift is determined by summing up all the obtained and recorded diesel fuel consumption values:

$$
\mathrm{C}_{\text {tot. g-d-f. p-s-s. }}=\mathrm{C}_{3 \text { g-d-f. }}+\mathrm{C}_{4 \text { g-d-f. }}+\ldots \ldots \ldots \ldots \mathrm{C}_{\mathrm{n}+1 \text { g-d-f.; }} \text {; }
$$


where, $\mathrm{C}_{3 \mathrm{~g} \text {-d-f. }}$ - the diesel consumption per third haul, $1 ; \mathrm{C}_{4 \mathrm{~g}-\mathrm{d}-\mathrm{f} \text { - }}$ the diesel consumption per forth haul, $1 ; \mathrm{C}_{\mathrm{n}+1}$ g-d-f.- the diesel consumption for all subsequent haul pairs per single shift, 1 .

\subsubsection{3rd stage}

Using the values obtained by formulas 5 and 6 , the rate of diesel fuel replacement with natural gas is determined according to the data of per-single-shift monitoring:

$$
\mathrm{R}_{\text {rep. p-s-s. }}=1--\frac{\mathrm{C}_{\text {tot. } \mathrm{g} \text {-d-f. p-s-s. }}}{\mathrm{C}_{\text {tot. d-f. p-s-s. }}} ;
$$

If it is necessary to determine the replacement ratio in percentage terms, the formula (9) will have the following form:

$$
\mathrm{R}_{\text {rep. p-s-s. }}=\left(1-\frac{\mathrm{C}_{\text {tot. g-d-f. p-s-s. }}}{\mathrm{C}_{\text {tot. d-f. p-s-s. }}}\right) \times 100 \% \text {; }
$$

\subsection{Per-day monitoring}

The per-day monitoring should be carried out on the same EUHT consistently and throughout one day. After day-shift monitoring, night-shift monitoring is carried out immediately.

At different times of day and at different seasons (especially in winter), there are noticeable external influences that affect the replacement rate evaluation, namely: changes in ambient temperature during day and night, and at different seasons; driving style of haul truck driver at different times of day, etc. In this regard, when operating a EUHT, $\mathrm{R}_{\text {rep. }}$ indicator values may vary depending on the time of day and season.

When determining the rate $\mathrm{R}_{\text {rep. }}$ of diesel fuel replacement with liquefied natural gas per one day, it is necessary to carry out one day-shift and night-shift monitoring. Using the values of the rate of diesel fuel replacement with liquefied natural gas, obtained by formula 7 , according to the data of single-day-shift and single-night-shift monitoring, the average value of the rate of diesel fuel replacement with liquefied natural gas per day is determined:

$$
\mathrm{R}_{\text {rep. p-d. }}=\frac{\mathrm{R}_{\text {rep.p-s-s (p.d.s.) }}+\mathrm{R}_{\text {rep.p-s-s (p.n.s.) }}}{2} ;
$$

where, $R_{\text {rep. p-d. }}$ - the replacement rate per day; $R_{\text {rep.p-s-s (p.d.s.)- }}$ the replacement rate per day shift; $R_{\text {rep.p-s-s }(\text { p.n.s. })}$ - the replacement rate per night shift;

If it is necessary to determine the replacement ratio in percentage terms, the formula 9 will have the following form:

$$
\mathrm{R}_{\text {rep. p-d. }}=\left(\frac{\mathrm{R}_{\text {rep.p-s-s }} \text { (p.d.s.) }}{2} \mathrm{R}_{\text {rep.p-s-s (p.n.s.) }}\right) \times 100 \% ;
$$

If an on-board cryogenic fuel system is equipped with a gas flow measurement kit, after each day and night shift, using the obtained gas flow day-shift $\mathrm{C}_{\text {g.f.d-s. }}$ and night-shift $\mathrm{C}_{\text {g.f.n-s. }}$ rates, we determine the total gas consumption per one day $\mathrm{C}_{\text {tot.g..p.o.d., }}$ when operating mixed gas-diesel-fuelled EUHT:

$$
\mathrm{C}_{\text {tot.g.g.p.o.d. }}=\mathrm{C}_{\text {g.f.d-s. }}+\mathrm{C}_{\text {g.f.n-s.s.; }}
$$


The obtained value of the total gas consumption $\mathrm{C}_{\text {tot.g.c.p.o.d. }}$ per one day shows the volume $\left(\mathrm{m}^{3}\right)$ of consumed natural gas required for diesel fuel replacement per one day

$$
\mathrm{C}_{\text {tot.g.c.p.o.d. }} \rightarrow \Delta \mathrm{C}_{\text {p.o.d. }}=\left(\Delta \mathrm{C}_{\mathrm{p} \text {-s-s.(p.d.s. })}+\Delta \mathrm{C}_{\mathrm{p} \text {-s-s.(p.n.s.) }}\right)
$$

where, $\Delta \mathrm{C}_{\text {p.o.d. }}$ the replaced diesel volume per one day, $1 ; \Delta \mathrm{C}_{\mathrm{p} \text {-s-s.s.(p.d.s.) }}$ - the replaced diesel volume per one day-shift, $1 ; \Delta \mathrm{C}_{\text {p-s-s.(p.n.s.) }}$ - the replaced diesel volume per one night-shift, 1 .

A representative sample is a sample of data for which the following conditions hold:

- the average EUHT speed varies by no more than $1 \mathrm{~km} / \mathrm{h}$;

- the weight of the hauled exploded rock mass per cycle differs by no more than 5 tons;

- the cycle haul distance differs by no more than $0,5 \mathrm{~km}$.

The calculation of the volume of consumed diesel fuel is made after filtering the information obtained during the monitoring period (cycle, shift, day). When calculating the amount of consumed diesel fuel, it is necessary to take into account graphic and digital noise, haul truck refueling and waiting periods in the areas of loading and unloading.

\subsection{Evaluation of the economic efficiency of the operation of upgraded haul trucks equipped with on-board cryogenic fuel systems}

The evaluation of the economic efficiency of the operation of haul trucks equipped with onboard cryogenic fuel systems means establishing the reduced annual costs $\Sigma_{\text {r.a.c. }}$ taking into account capital and operating costs:

$$
\Sigma_{\text {r.a.c. }}=\Sigma_{\text {c.c. }} \mathrm{E}+\Sigma_{\text {o.c. }}
$$

where, $\Sigma_{\text {r.a.c. }}-$ the reduced annual costs, rub./year; $\Sigma_{\text {c.c. }}-$ capital costs, rub.; E - the established investment efficiency ratio; $\Sigma_{\text {o.c. }}$ - operating costs, rub.

The reduced annual costs are calculated for both basic and upgraded haul trucks. Taking into account the fact that haul trucks operate in identical mining, engineering and technological conditions the formula for reduced annual costs takes the form:

$$
\Pi_{\mathrm{i}}=\Sigma_{\text {h.t. }} \mathrm{E}_{\mathrm{i}}+\left(\Sigma_{\text {c.f. }}\right)
$$

where, $\Sigma_{\text {h.t.- }}$ the cost of haul truck, (rub.); E - the established investment efficiency ratio; $\mathrm{i}$ - the index of the haul truck under consideration (basic or upgraded); $\Sigma_{\text {c.f.- }}$ the cost of fuel, (rub.).

The cost of fuel is calculated by the following formula:

$$
\Sigma_{\text {c.f }}=\left(\mathrm{A}_{\text {tot. }} \mathrm{Rna}+\mathrm{Wb}\right)+\mathrm{G}
$$

where, $A_{\text {tot. }}$ - the total fuel consumption per haul, $t ; \mathrm{R}$ - the number of hauls per day; $\mathrm{n}$ - the number of working days per year; a - cost of 1 ton of fuel consumed (in case of a change in the cost of fuel during the year, the average value for the year is taken), rub.; $\mathrm{W}$ - the rated engine capacity, $\mathrm{kW} ; \mathrm{b}$ - the annual rated engine capacity tariff, (rub. per $\mathrm{kW}$ ); the total annual cost of fuel delivery to the place of haul truck fuelling $\mathrm{G}$, (rub).

If the engine capacity of basic and upgraded haul trucks is identical, and if the cost of fuel delivery to the place of haul truck refueling is already included in the cost of 1 ton of consumed fuel, then the second $\mathrm{Wb}$ and third $\mathrm{G}$ terms of formula (15) can be neglected.

The calculation of the actual service life of an on-board cryogenic fuel system is described by the following expression. 


$$
\mathrm{T}_{\text {a.s.l. }}=\frac{\Sigma \mathrm{T}_{\text {s.f.a. }}}{\mathrm{P}} ;
$$

where, $\mathrm{T}_{\text {a.s.l. }}$ - the average service life; $\Sigma \mathrm{T}_{\text {s.f.a. }}-$ the sum of failures of all (on-board cryogenic fuel system - OCFS) units; $\mathrm{P}$ - the number of OCFS units.

In turn, the time between one unit failures is calculated as:

$$
\mathrm{T}_{\text {s.f.a. }}=\left(\frac{\mathrm{N}-\mathrm{n}}{\mathrm{N}}\right) \times \mathrm{t}
$$

where, $\mathrm{N}$ - the number of OCFS units; $\mathrm{n}$ - the number of OCFS units failed by time $\mathrm{t} ; \mathrm{t}$ - the operation time to failure, meter hours.

Analysis of the causes of repairs of on-board cryogenic fuel systems with the aim of predicting and preventing unplanned downtime is performed by means of standard statistical facilities (numerical or graphical distribution of the causes of repairs in operation).

\section{Conclusion}

The presented procedure for assessing performance indicators of on-board cryogenic fuel systems allows to qualitatively and quantitatively determine the rate of diesel fuel replacement by liquefied natural gas, when operating gas-diesel haul trucks, to assess the economic efficiency of the operation of haul trucks equipped with on-board cryogenic fuel systems, to determine the actual service life of on-board cryogenic fuel systems and the time between failures of a single on-board cryogenic fuel unit. However, the current lack (due to the innovativeness of this research field) of sufficient data on the statistics of the operation of haul truck on-board cryogenic fuel systems, gives prerequisites for further improvement of this kind of procedures in the light of dynamically developing projects concerning the use of liquefied natural gas as a motor fuel.

\section{References}

1. G.M. Dubov, D.S. Trukhmanov, A.A. Chegoshev, V.E. Ashikhmin, E3S Web Conf., 41, 03008 (2018)

2. M.L. Khazin, PJPME, 19:1, 56 (2019)

3. J. Osorio-Tejada, E. Llera, S. Scarpellini, WIT Transactions on The Built Environment, 168, 235 (2015)

4. V.Y. Koptev, A.V. Kopteva, IOP Conf. Ser.: Earth Environ. Sci., 87:2, 022010 (2017)

5. K. Cheenkachorn, C. Poompipatpong, C.G. Ho, Energy, 53, 52 (2013)

6. H.A.A. Wahhab, M.A. Ismael, A. Aziz, M.R. Heikal, AJAS, 10:2, 88 (2017)

7. I.V. Kuznetsov, I.A. Panachev, G.M. Dubov, S.A. Nohrin, Handbook. An Engineering Journal, 4, 19 (2019)

8. A.G. Goncharuk, V.I. Havrysh, V.S. Nitsenko, IJETP, 14:2-3, 226 (2018)

9. A. Thiruvengadam, M. Besch, D. Carder, A. Oshinuga, JA\&WMA, 66:11, 1045 (2016)

10. D.G. Carmichael, B.J. Bartlett, A.S. Kaboli, Int J Min Reclamat Environ, 28:1, 4 (2014) 
11. D.C. Quiros, J. Smith, A. Thiruvengadam, T. Huai, Atmospheric Environ., 168, 36 (2017)

12. A.S. Ivanov, I.A. Anisimov, E.M. Chikishev, Autogas Filling Complex + Alternative Fuel, 12:81, 17 (2013)

13. A. Arteconi, C. Brandoni, D. Evangelist, F. Polonara, Appl. Energy, 87:6, 2005 (2010)

14. N. Dronniou, J. Kashdan, B. Lecointe, K. Sauve, D. Soleri, SAE International Journal of Engines, 7:2, 873 (2014) 